\title{
Non-Fasting Lipid Profiles and Cardiovascular Risk Assessment
}

\author{
Vijaya Marakala.
}

Senior Lecturer, Department of Biochemistry, International M edical School, M anagement \& Science University, Shah Alam, Selangor, M alaysia.

\section{ABSTRACT}

Current practice for lipid profile estimation worldwide is with fasting sample. Many studies involved large population carried out recently with non-fasting status and their observation suggest that fasting is not necessary for lipid profile investigation. This review mainly focussing on outcome of some of the studies conducted with non-fasting status and their application in order to assess cardiovascular events.

KEY WORDS: Non-Fasting, lipids, Lipid Profile, Cardiovascular Risk.

Address for correspondence: Dr. Vijaya M arakala, Senior Lecturer, Department of Biochemistry, International M edical School, Management \& Science University, Shah Alam, Selangor, Malaysia.

E-Mail: vkunder637@gmail.com

\begin{tabular}{|c|c|c|}
\hline \multicolumn{3}{|c|}{ Online Access and Article Informtaion } \\
\hline \multirow{2}{*}{$\begin{array}{l}\text { Quick Response code } \\
\text { Dol: } 10.16965 / \text { ijims.2015.137 }\end{array}$} & nternational Jour & $\begin{array}{l}\text { tegrative Medical Sciences } \\
\text { ciences.com }\end{array}$ \\
\hline & $\begin{array}{l}\text { Received: 15-12-2015 } \\
\text { Reviewed: 15-12-2015 }\end{array}$ & $\begin{array}{l}\text { Accepted: 27-12-2015 } \\
\text { Published: 31-12-2015 }\end{array}$ \\
\hline Source of Funding: Self & & interest: None \\
\hline
\end{tabular}

Cardiovascular risk predictions are usually done by measuring plasma lipids, lipoproteins and apolipoproteins. The test includes total cholesterol, HDL cholesterol, LDL cholesterol and triglycerides. Since long time lipid profile measurement done with fasting state mainly because postprandial triglycerides remain elevated for several hours and the Friedewald equation, used for calculation of LDL cholesterol [1]. Nowadays many laboratories measure LDL cholesterol directly rather than using Friedewald equation. M any recent studies concluded that nonfasting lipid profiles change minimally in response to food intake. The most interesting part is that non-fasting triglycerides levels may be even better predictor of cardiovascular risk as compared to fasting triglycerides $[2,3]$. Bansal et. al in their prospective cohort study they compared fasting and nonfasting triglycerides and the incidence of a cardiovascular event in a female population. The large-scale Copenhagen prospective cohort study, which had a patient follow-up for up to
26 years reported that postprandial hypertriglyceridemia showed an independent risk for a cardiovascular event, compared with that of fasting concentration [2].

It should be keep in mind that both nonfasting and postprandial are not equal as non-fasting sample means blood draw at any time without knowledge of the time of previous meal while post prandial implies a sample at a fixed time after a standard meal. Moreover, triglycerides increase step wise after fat diet, therefore, nonfasting triglycerides would vary depending on time after meal with highest levels $4-5 \mathrm{~h}$ post prandially [3].

M ora et. al concluded in their study that general population cohort, elevated nonfasting triglyceride levels were associated with increased risk of MI, IHD, and death in men and women[4]. Their study was a prospective cohort trial which evaluated plasma lipid concentration at various postprandial times and determined if fasting versus nonfasting status differs in 
predicting cardiovascular events. Doran B et.al reported that the $C$ statistic for all-cause mortality in the group of individuals who fasted prior to LDL-C estimation was $0.59(95 \% \mathrm{Cl} 0.57$ 0.61 ) and was similar in those who were nonfasting $(0.58 ; 95 \% \mathrm{Cl} 0.56-0.60)$. Testing for interaction between LDL-C categories and fasting status was not significant (Pinteraction $=0.11$ ). Results using the secondary outcome of cardiovascular mortality were similar. [5]. Their cross-sectional data suggest that most people eat less fat during normal food intake than during a fat tolerance test, simply because individuals in the general population have less plasma triglycerides in response to normal food intake than during a fat tolerance test of 1-gram dairy cream per kilogram of body weight. The only modest increase in triglyceride levels during normal food intake together with their demonstration of high predictive ability of nonfasting triglycerides for risk of MI, IHD, and death opens the possibility that nonfasting rather than fasting triglyceride levels should be used for risk prediction. If implemented, this would simplify blood sampling for lipid measurements for patients with diabetes, the fasting requirement might be an important safety issue because of problems with hypoglycaemia [5]. Sidhu et. al reported that fasting for routine lipid level determinations is largely unnecessary and unlikely to affect patient clinical risk stratification, while nonfasting measurement might improve patient compliance and safety [6].

Postprandial lipaemia is gaining importance with recent reports showing nonfasting TG to independently predict atherosclerosis [7].Postprandial lipids may play an important role in the pathogenesis of cardiovascular disease because postprandial triglyceride-rich remnant lipoproteins can penetrate the endothelial cell layer and reside in the subendothelial space, where they can contribute to the formation of foam cells, a hallmark of early atherosclerosis $[8,9,10]$. Triglycerides and remnant lipoprotein concentrations both typically increase to their peaks by approximately 4 hours and decline thereafter [11]. This support the broad hypothesis that atherosclerosis is, at least in part, a "post prandial phenomenon [2,12-14].

Non-fasting sample can also be utilized in order to evaluate CAD patients hospitalized in the acute phase where waiting for obtaining a fasting sample may delay institution of specific treatment [15].

M ichael J. et.al studied fasting vs nonfasting in paediatrics age groups and they concluded that comparison of cholesterol screening results for a nonfasting group of children compared with results for a similar fasting group resulted in small differences that are likely not clinically important [16].

\section{SUM M ARY}

Even though fasting status for lipid profile estimation is the gold standard since long time mainly because LDL cholesterol calculated using Friedewald formula but nowadays most of the laboratories measures directly LDL cholesterol. Several studies have demonstrated that lipid profile estimation during nonfasting status exhibit minimal and clinically insignificant changes when compared to fasting status. M easurement of non-fasting lipid levels reduces inconvenience for patient and improves patient compliance towards lipid testing and lipid lowering therapies. So cardiovascular risk assessment need not require fasting status as non-fasting lipid profiles are as good as fasting status.

\section{REFERENCES}

[1]. Campos H, Khoo C, Sacks FM. Diurnal and acute patterns of postprandial apolipoprotein B-48 in VLDL, IDL, and LDL from normolipidemic humans. Atherosclerosis. 2005 Aug 31;181(2):345-51.

[2]. Bansal S, Buring J E, Rifai N, M ora S, Sacks FM, Ridker PM.Fasting compared with nonfasting triglycerides and risk of cardiovascular events in women. JAM A. 2007 Jul 18; 298(3):309-16.

[3]. Nordestgaard BG, Benn M, Schnohr P, TybjaergHansen A Nonfasting triglycerides and risk of myocardial infarction, ischemic heart disease, and death in men and women. JAMA. 2007 Jul 18; 298(3):299-308.

[4]. Mora S, Rifai N, Buring JE, Ridker PM. Fasting compared with nonfasting lipids and apolipoproteins for predicting incident cardiovascular events. Circulation. 2008 Sep 2;118(10):993-1001. 
[5]. Doran B, Guo Y, Xu J, Weintraub H, M ora S, Maron DJ, Bangalore S. Prognostic Value of Fasting Versus Nonfasting Low-Density Lipoprotein Cholesterol Levels on Long-Term M ortality Insight From the National Health and Nutrition Examination Survey III (NHANES-III). Circulation. 2014 Aug 12;130(7):546-53.

[6]. Sidhu D, Naugler C. Fasting time and lipid levels in a community-based population: a cross-sectional study. Archives of internal medicine. $2012 \mathrm{Dec}$ 10;172(22):1707-10.

[7]. Anja S, Lindman, Veierød M B, Tverdal A, Pedersen JI, Selmer R. Non fasting triglycerides and risk of cardiovascular death in men and women from the Norwegian Counties Study. Eur J Epidemiol 2010:25;789-98.

[8]. Daugherty A, Lange LG, Sobel BE, Schonfeld G. Aortic accumulation and plasma clearance of beta-VLDL and HDL: effects of diet-induced hypercholesterolemia in rabbits. J Lipid Res. 1985;26(8):955963.

[9]. Rapp JH, Lespine A, Hamilton RL, et al. Triglyceride rich lipoproteins isolated by selected-affinity antiapolipoprotein B immunosorption from human atherosclerotic plaque. Arterioscler Thromb. 1994; 14(11):1767-1774.
[10]. Proctor SD, Mamo JC. Retention of fluorescent labelled chylomicron remnants within the intima of the arterial wall-evidence that plaque cholesterol may be derived from post-prandial lipoproteins. Eur J Clin Invest. 1998;28(6):497-503.

[11]. Boquist S, Ruotolo G, Tang R, et al. Alimentary lipemia, postprandial triglyceride-rich lipoproteins, and common carotid intima-media thickness in healthy, middle-aged men. Circulation. 1999;100(7):723- 728.

[12]. Ginsberg HN. New perspectives on atherogenesis: role of abnormal triglyceride-rich lipoprotein metabolism. Circulation. 2002;106(16):2137-2142.

[13].Zilversmit DB. Atherogenesis: a postprandial phenomenon. Circulation. 1979;60(3):473-485.

[14]. Karpe F. Postprandial lipoprotein metabolism and atherosclerosis. J Intern M ed. 1999;246(4):341-355.

[15]. Srilakshmi P, Gopinath M F, Vijaya Bhaskar M, Rambabu K, Reddy GS. Non-fasting samples for estimation of serum lipid levels in patients with coronary artery disease. J Clin Sci Res 2014;3:206209.

[16]. Steiner MJ, Skinner AC, Perrin EM . Fasting might not be necessary before lipid screening: a nationally representative cross-sectional study. Pediatrics. 2011 Sep 1;128(3):463-70.

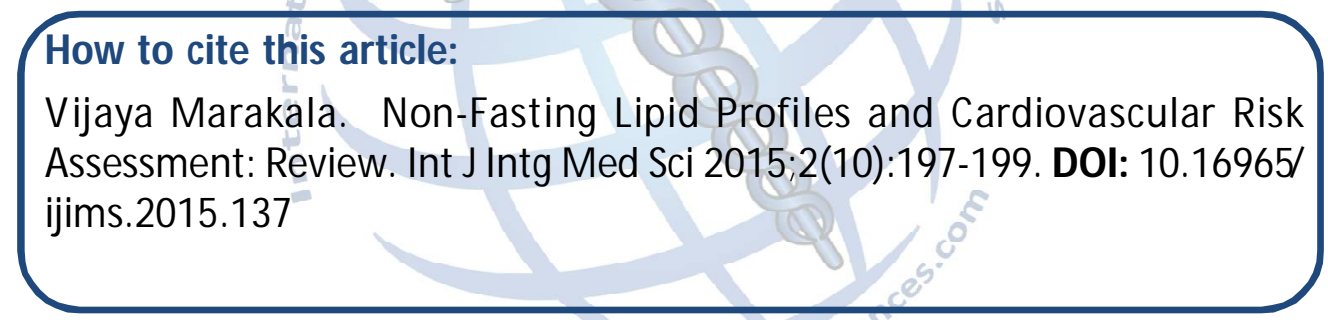

